\title{
O TRABALHO DOCENTE NAS PÁGINAS DE EDUCAÇÃO \& SOCIEDADE EM SEUS (QUASE) 100 NÚMEROS
}

\author{
MENGA LÜDKE* \\ Luiz Alberto Boing ${ }^{* *}$
}

\begin{abstract}
RESUMO: Este texto focaliza artigos relacionados ao trabalho docente, em Educação \& Sociedade, um dos mais importantes e representativos periódicos na área da educação, nos seus (quase) 100 números. São ressaltados aspectos que receberam maior atenção nos artigos, de modo especial aqueles que se baseiam em pesquisas realizadas pelos seus autores. A partir do quadro assim formado, são discutidos pontos mais sensíveis da grande questão, quando se considera a realidade brasileira, à luz da literatura recente, representada, sobretudo, por autores mais próximos aos interesses de pesquisa dos redatores deste texto.
\end{abstract}

Palavras-chave: Trabalho docente. Profissão. Profissionalismo. Formação docente.

\section{Teacher's WORK IN THE Pages OF EDUCAÇÃO \& SOCIEDADE IN ITS (ALMOST) 100 ISSUES}

ABSTRACT: This text focuses on the articles related to teacher's work in the (almost) 110 issues of Educação \& Sociedade, one of the most important and representative journals in the area of education. It highlights the aspects that received major attention in the papers, more particularly those that are based on research carried out by their authors. Within this framework, it discusses the sorest points of the great issue, when one considers the Brazilian reality to the light of recent literature, that is essentially represented by authors closer to the research interests of the writers of this text.

Key words: Teacher's work. Profession. Professionalism. Teacher's training.

\footnotetext{
* Doutora em Educação e professora titular da Pontifícia Universidade Católica do Rio de Janeiro (PUC-RJ).E-mail: menga@edu.puc-rio.br

** Doutorando em Educação pela Pontifícia Universidade Católica do Rio de Janeiro (PUC-RJ). E-mail: lula@pedroarrupe.com.br
}

Educ. Soc., Campinas, vol. 28, n. 100 - Especial, p. 1179-1201, out. 2007 


\section{Introdução}

$\mathscr{P}$

ara o presente artigo, fizemos um levantamento sobre o trabalho docente junto aos quase 100 números de Educação \& Sociedade, como revista representativa das melhores publicações na área educacional, para, em seguida, levantar os aspectos mais significativos, cotejá-los com a realidade brasileira e discuti-los à luz da literatura pertinente, de modo especial pela contribuição de autores mais ligados às nossas preocupaçóes de pesquisa. Encontramos 41 números da revista digitalizados na Scientific Electronic Library On-Line (sCIELO), do 58 ao 98. Os anteriores foram consultados em diferentes bibliotecas.

Não se pode estender a expressão "trabalho docente" a todos os volumes de E⿺辶万S sem alguma precaução, pois sua utilização remonta apenas ao início dos anos de 1990. Antes, terminologias como "trabalho educativo" e "trabalho pedagógico" eram mais utilizadas, mas não queriam dizer exatamente a mesma coisa, embora possamos encontrar muitos elementos comuns entre um termo e outro. Consideramos, então, o conteúdo dos artigos para destacar aqueles que tratam de assunto relativo ao que hoje em dia se procura entender como trabalho docente.

Aspectos mais significativos ressaltados

A partir do levantamento e da leitura dos artigos que tratam do tema trabalho docente, procuramos agrupar aspectos mais significativos ressaltados por seus autores, em função de sua repercussão na realidade brasileira, tal como os vemos. Chegamos, assim, a quatro blocos, que recobrem os itens trabalhados pelos articulistas.

\section{Sindicatos e organizações docentes}

Arroyo (1980), já no n. 5, intitulado "Educador = Trabalhador", estabeleceu uma importante conexão entre o trabalho dos docentes nas escolas e a transformação da nossa sociedade. Segundo o autor, os professores constituíram "uma das primeiras categorias de trabalhadores e assalariados a sair à rua, reivindicando e se organizando" (p. 17).

Só no n. 37 o assunto volta a ser tratado, no artigo de Castro (1990), que confirma a esperança de Arroyo na força das lutas sindicais 
de professores, insistindo na importância do trabalho docente para o desenvolvimento de uma nação e a decorrente necessidade do seu reconhecimento público.

O tema esperou ainda 40 números para voltar a aparecer. No n. 77, um artigo de Sobreira (2001), baseado em estudo iniciado em sua dissertação de mestrado, sobre o nascimento do Sindicato Estadual dos Profissionais de Educação do Rio de Janeiro (SEPE-RJ), fala da predominância de ideais políticos na origem desse sindicato, voltados para a redemocratização do país, no final dos anos de 1970, graças à participação de seus fundadores, quase todos pertencentes a partidos políticos de esquerda. Esses ideais, entretanto, foram cedendo lugar a reivindicaçôes mais imediatistas, principalmente de cunho salarial, à medida que o movimento se massificava. Passados mais de vinte anos dos fatos analisados, em seu artigo de 2001, o autor considera que essa redução parece representar uma tendência de todos os movimentos sindicais docentes.

Mais 17 números esperaram por um novo tratamento do assunto. Em artigo de Gentili e outros (2004), no n. 89, ele é tratado dentro do quadro de políticas gerais marcadas pelo selo da globalização. Os autores constatam, como Sobreira havia feito, a ligação quase exclusiva das lutas sindicais com as condiçôes salariais e de trabalho dos professores, o orçamento para a educação, a precariedade de incentivos e estímulos econômicos para o setor e as normas que regulam o trabalho nas instituiçõos educativas e o aperfeiçoamento profissional.

\section{O trabalho docente e as políticas públicas}

Neste item registramos uma série de artigos, alguns dos quais se referindo a pesquisas efetuadas por seus autores. Em geral, eles se reportam ao contexto atual marcado pela tendência à globalização, com todas as repercussōes que abrangem não apenas o setor educacional, mas a sociedade como um todo.

No n. 74, encontramos um artigo (Therrien \& Loiola, 2001) que representa uma linha de pesquisa desenvolvida há longo tempo por um dos autores (Therrien), centrada sobre "o saber e a prática social do educador" e apoiada em estudiosos da prática docente. O artigo apresenta o conceito de ergonomia, focalizando a análise do trabalho a 
partir da descrição e explicação da atividade humana numa situação concreta, comportando dois pólos interligados: as situações e as pessoas. O lado humano envolvido no ensino, representado pelos alunos e professores, constitui uma realidade dinâmica, complexa e imponderável, impossível de ser inteiramente prevista, como parece subentender a burocracia estatal. Esta constatação está na base da crítica que os autores fazem às reformas educativas brasileiras da década de 1990, ligadas a duas vertentes: a lógica da pedagogia por competências e a preocupação com a avaliação de resultados, mensuráveis e comparáveis com índices internacionais.

No n. 89, o artigo de Gentili e outros (2004), já mencionado no bloco relativo aos sindicatos e lutas docentes, traz uma interessante discussão sobre a centralidade da "conflitividade educativa", no campo dos conflitos sociais e políticos em países da América Latina, e seus reflexos sobre o trabalho docente. Nas duas últimas décadas, essa conflitividade tornou-se evidente no afastamento crescente entre as reformas educativas propostas e as condições reais de sua implementação, nos campos político, econômico-financeiro e normativo. A despeito de sua centralidade, as lutas das organizações sindicais têm alcance limitado, reduzidas em geral a mobilizaçôes por demandas salariais. Dentro desse quadro, os autores propõem uma integração de reivindicações mais amplas em uma politica docente integral. De um lado, os movimentos docentes reivindicatórios não alcançam questôes de âmbito estrutural, para ultrapassar a fundada falta de confiança em ocupantes de altos cargos político-administrativos (ministros, secretários), devida à sua curta permanência nos postos. De outro, sofrem as políticas públicas, ou inovações no campo educacional, pelas pouquíssimas possibilidades de êxito, se não encontrarem apoio em soluções no âmbito estrutural (p. 1.257).

No n. 92, Oliveira (2005), também focalizando países da América Latina, analisa a influência de "regulaçôes" emanadas de organismos internacionais sobre os sistemas educacionais desses países e suas conseqüências sobre a organização e estruturação da escola e do trabalho de seus professores. A autora chama a atenção para a distinção entre os conceitos de regulação e regulamentação, respectivamente ligados aos processos e aos produtos ou fins de um sistema determinado. A disparidade entre o discurso geral e as condiçôes reais das escolas tem provocado um "sentimento de inadequação e de dúvida muito freqüente 
entre os professores", que reforça no trabalho coletivo a justaposição de tarefas individuais, distantes das lutas de um movimento pela emancipação social. As políticas apontam para o global e a realidade prende os professores com "pés de chumbo" à situação local (p. 772).

\section{Profissão, profissionalidade, identidade e desenvolvimento profissional}

Um artigo de Haguette (1991), publicado no n. 38, apresenta três noções importantes ligadas ao conceito de profissão no magistério, por contraste e por aproximação. Inicia com a noção de "bico", quando a ocupação se situa numa estrutura social patrimonialista, em que a relação de trabalho é refém do autoritarismo e arbítrio do dono do poder, passando pela idéia de vocação, que implica uma escolha afetiva baseada num chamado pessoal, chegando à noção de profissionalismo, oposto à vocação por ser anônimo, universal, neutro e burocrático.

No n. 48, um artigo de Gatti e outras (1994), com base em pesquisa feita nos estados de São Paulo, Minas Gerais e Maranhão, destaca várias características próprias de professores do $1^{\circ}$ grau. Entre elas, o predomínio de mulheres nesse nível de ensino (94\%) e a concentração entre 35 e 45 anos de idade (49\%). Cerca de $40 \%$ dos professores dos estados de São Paulo e Minas declararam exercer o magistério em mais de uma instituição. Para 16\% dos informantes, o salário do magistério é a única fonte para a sua manutenção ou de sua família, subindo para $24 \%$ os que declaram que esse salário é fundamental para a família, ainda que não seja a única fonte de seu sustento. Quanto às condiçōes de trabalho, as informaçōes dão conta do número médio de alunos por professor: 38 no Maranhão, 31 em Minas e 33 em São Paulo, o que não parece tão elevado em comparação com números mais recentes. Os informantes declaram também que despendem, em média, quatro horas por semana no preparo de aulas e três horas na correção de exercícios e provas. O pagamento de horas extras assinala uma diferença entre os estados: em São Paulo, 77\% dos informantes declaram recebê-lo, em Minas $42 \%$ e no Maranhão $27 \%$. O estudo traz também informaçôes sobre a escolha do magistério como a profissão preferida, aparecendo apenas em $41 \%$ das respostas, sendo que $40 \%$ chegaram a declarar que gostariam de optar por outra carreira, $71 \%$ deles apontando a não valorização da atual carreira, o baixo salário e o trabalho desgastante como razões dessa possível opção. Tratando da 
realização pessoal e imagem social do magistério, hoje bastante desvalorizado, $83 \%$ dos informantes apontam o salário indigno como o fator mais importante para essa desvalorização. A grande maioria das respostas apontou as atividades em sala de aula e as boas relações afetivas no trabalho como os aspectos mais gratificantes. Já para os fatores de frustração, as respostas se dividiram, $27 \%$ apontando o baixo salário, $23 \%$ a falta de condições de atuação profissional e $23 \%$ a falta de formação e atualização do professor. Vale registrar também, nesse aspecto, que $16 \%$ mencionaram as más relações no trabalho e as múltiplas exigências extra-aula como fatores de frustração. As autoras chamam a atenção para a importância atribuída pelos informantes às interações com as pessoas para a qualidade do trabalho exercido, mais do que a "aspectos técnicos abstratos" (p. 255).

No n. 68, o artigo de Melo (1999) defende o desenvolvimento de uma identidade profissional pelo professor já a partir de sua formação inicial, para evitar o risco de se tornar mero executor das políticas emanadas de órgãos estatais. Nas sugestôes encaminhadas ao Plano Nacional de Educação, através da CNTE, aparece claramente essa insistência no sentido da profissionalização no magistério.

No n. 74, Lüdke (2001), baseando-se em pesquisa realizada sobre a socialização profissional de professores (Lüdke, 1996), destaca a formação inicial e o trabalho do professor como bases para a construção da sua identidade profissional. Com apoio em outro estudo (Lüdke, 2001), aponta a importância da pesquisa realizada pelo professor da educação básica para seu próprio desenvolvimento profissional.

Em artigo do n. 85, Freitas (2003) denuncia a intenção das reformas educacionais latino-americanas de retirar das universidades a formação de professores e de alterar a tradicional lógica disciplinar que sempre orientou essa formação. Para a autora, isso representa um grave recuo para a profissionalização de professores, significando mesmo uma desprofissionalização.

Lüdke e Boing (2004), no n. 89, discutem os conceitos de profissão e de profissionalidade no magistério, levantando também o perigo de um processo de desprofissionalização, decorrente da desvalorização e desvirtuamento dos salários dos professores, a partir dos anos de 1960 , e, em época mais recente, com a entrada de novas demandas sobre o trabalho do professor. Os autores alertam, ainda, para dois fenômenos 
correntes que agravam esse processo de desprofissionalização: o risco velado da entrada das Tecnologias da Informação e Comunicação (TICs) nas escolas, financiada a partir de um desvio do salário dos professores, e a terceirização crescente de funções ligadas à atividade-fim na escola privada, onde o pessoal docente é transformado em pessoa jurídica para a prestação de serviços educacionais.

\section{A fisionomia do trabalho docente hoje}

Em artigo do n. 85, Freitas (2003) trata da flexibilização do trabalho docente como um dos temas-chave para a discussão da Conferência Regional "O desempenho dos professores da América Latina e Caribe: novas prioridades”, em julho de 2002, em Brasília. Em suas análises, Freitas alerta para o problema da avaliação dos professores, assumida como uma das prioridades pelos países participantes. Para a autora, a proposta de avaliação discutida supunha a flexibilização do trabalho docente, centrada em competências técnicas e não na "formação do educador sócio-histórico" e nem na "docência como base da formação dos profissionais da educação” (p. 1.106), e as lutas históricas das quais a autora é porta-voz. Sobre a proposta de criação do sistema nacional de certificação de competências docentes, indício do alinhamento das políticas nacionais aos consensos regionais latino-americanos, conclui que o resultado penderá mais para o lado da regulação do que da profissionalização do trabalho docente.

O n. 89 traz vários artigos bastante ligados ao nosso tema, focalizando, de modo especial, a evolução do trabalho do professor e suas diferentes configuraçôes, a partir das pressōes que vem sofrendo no "império da globalização".

Oliveira (2004), bem dentro do contexto desse "império" e com base em estudos iniciados em sua tese de doutorado, analisa a reestruturação do trabalho docente, face à ampliação de suas funções, e a própria desvalorização que o coloca em situação ambígua entre o profissionalismo e a proletarização, correndo mesmo o risco de desprofissionalização. Não chegando a se constituir como uma profissão, inteiramente, o magistério sofre as conseqüências da definição desse conceito, de profissão, proposta pela sociologia das profissões, que ajudou “a legitimar e perpetuar o status quo" (p. 1.137). Uma tentativa de 
flexibilização e mesmo de desregulamentação da legislação vem provocando uma precarização nas relações de emprego, mais do que nas de trabalho, segundo a autora. As novas exigências feitas pelas reformas propostas ao trabalho do professor, sem que novas condições lhes sejam asseguradas nas escolas, parecem compor um cenário no qual predomina uma forma antiga para um aluno novo.

Inspirada em conceitos propostos por Bernstein e Ball, Santos (2004), no mesmo n. 89, toca em cheio em uma das questôes centrais do nosso sistema educacional: a avaliação do desempenho, de alunos e de professores. Com perspicácia, a autora lembra que os aspectos mais facilmente mensuráveis são os mais acessíveis a um esforço de accountability, sendo que grande parte dos aspectos positivos desse desempenho dificilmente se revela a instrumentos comuns de mensuração, resultando, portanto, na predominância de pontos negativos no cômputo final. Isso vai provocando uma redução do trabalho de professores e alunos aos itens "esperados pelas políticas", sacrificando-se assim aqueles menos visíveis, mas possivelmente tão ou mais valiosos ( $p$. 1.152). A própria identidade do docente sofre, desse modo, o risco de redução ao que é esperado. A autora alerta para a importância de uma preparação teórica sólida do futuro professor, para precavê-lo contra esses riscos.

Barreto (2004), também no n. 89, traz à discussão uma série de conceitos que acompanham a entrada das TIC no nosso sistema escolar e suas implicações para a formação e o trabalho docentes. As noções de "competências" e de "atividades" entram logo em concorrência com a de trabalho e são acompanhadas pelas noções de "comodificação", "consumidores", "clientes", "pacotes", "produtos", contribuindo para que a educação seja vista cada vez mais como um setor de serviços. Até o professor começa a ser substituído pelo "monitor", em seus diferentes significados bem analisados pela autora (p. 1.186). A "Educação a Distância”, servida pelas TIC, na forma de educação continuada, começa a ganhar terreno sobre a formação inicial, menos beneficiada por financiamentos estatais. O binômio ensino-aprendizagem passa a sofrer um desequilíbrio no lado do ensino, muito sustentado pelos materiais alternativos do e-learning, insinuando um "novo lugar" para o professor na condição de profissional do ensino (p. 1.196). A autora vê aí uma possível desterritorialização da escola, contrária à sua forma historicamente construída, cedendo aos desafios da "globalização" e seu quadro 
de parâmetros mercadológicos, ao invés de assegurar sua defesa como direito e prática emancipatória. E chama a atenção para a importância da preparação do futuro professor, na formação inicial, para o trabalho docente com as TIC, não deixando essa tarefa essencial confiada primordialmente a técnicos.

Le Vasseur e Tardif (2004), também no n. 89, com base em estudos feitos na França, no Canadá e nos Estados Unidos, trazem uma intrigante questão, talvez ainda não tão sensível em nosso país como nos estudados, mas já servindo de alerta. Trata-se da intromissão de outros "profissionais" no trabalho nas escolas, para atender às necessidades das novas clientelas que tiveram acesso à educação básica. Alguns deles são especialistas de outras áreas, com formação no ensino superior, outros têm formação em nível técnico apenas, porém, em geral, não receberam preparação específica para o trabalho docente e entram em concorrência com o professor, o profissional de direito, genuinamente dedicado e legitimamente responsável pelo ensino. Os autores alertam que em alguns países, como a França, esses novos "profissionais" vêm se responsabilizando por grande parte do tempo consagrado ao trabalho de ensino, justamente com aqueles alunos que apresentam dificuldades, carecendo, na realidade, da atenção de verdadeiros profissionais do magistério.

Finalmente, em artigo que focaliza a dificuldade de implantação de práticas curriculares necessárias e oportunas, Sampaio e Marin (2004), no mesmo número, acabam denunciando "o desmonte da escola pública" e o "movimento de desvalorização das pessoas que usam a escola e fazem dela seu ponto de trabalho" (p. 1.223). O artigo traz dados ilustrativos das grandes transformações sofridas pelo nosso sistema educacional, com efeitos claros sobre a precarização do trabalho docente. Passamos de 3,3 a 31 milhões de alunos no ensino fundamental, de 1945 a 1994. Para atender a esse enorme crescimento, foi necessária a criação de muitas "funções docentes", que passaram de 280 mil, em 1960, a 1.377.665, em 1994. Para preenchê-las foi necessário recorrer a outros segmentos da população e a medidas pouco confiáveis para suprir sua qualificação, como autorizações provisórias e certificações restritas aos conteúdos disciplinares. No que se refere à preparação em curso superior, as autoras apresentam diferenças impressionantes, indicando $10 \%$ dos professores no Maranhão e $76 \%$ em São Paulo. Também quanto ao salário médio dos professores, há distâncias 
consideráveis entre as diferentes regiōes, indo de $\mathrm{R} \$ 221,22$ na Paraíba a R\$ 1.364,30 no Distrito Federal (dados de 2002). O artigo ainda chama a atenção para vários fatores que concorrem para a precarização do trabalho docente, focalizando de maneira especial a rotatividade, que leva o professor a diferentes postos ao longo da carreira, e a itinerância, que o leva a vários estabelecimentos concomitantemente.

\section{Nossos destaques}

O percurso que pudemos fazer num curto espaço de tempo, através das páginas de $E \mathcal{\&} S$, seguindo o fio condutor guiado pelo tema "trabalho docente", nos conduziu a muitos pontos importantes que fomos assinalando pelo caminho. A viagem foi rápida, mas a paisagem sempre interessante e reveladora de realidades, cujo conhecimento aprofundado não nos foi possível, pela rapidez do trajeto. Queremos, pelo menos, registrar alguns dos flashes que recolhemos, fixando aspectos que mais nos impressionaram, a partir dos ângulos que nos são mais familiares ou mais acessíveis, numa interlocução com autores cujas análises são mais próximas das que nós mesmos vimos desenvolvendo há algum tempo (Lüdke, 1988, 1996, 2006; Lüdke \& Cruz, 2005; Lüdke \& Boing, 2004; Boing, 2002).

\section{Trabalho docente: um tema polêmico}

O estudo que fizemos mostra que os professores são alvos ou estão no fogo cruzado de muitas esperanças sociais e políticas em crise nos dias atuais. As críticas externas ao sistema educacional cobram dos professores cada vez mais trabalho, como se a educação, sozinha, tivesse que resolver todos os problemas sociais.

A crítica pode vir também de dentro, como foi o caso de um trabalho de Enguita. O autor, que tantas vezes contribuiu para a construção e fortalecimento da profissão docente, lançou, em 2002, um verdadeiro libelo contra os professores, mais carregado de indignação do que de sua conhecida argúcia sociológica. A partir da experiência da escola de seu filho, que é pública, pergunta-se se essa escola continua pública. Respondendo, logo, que não mais, atribui a responsabilidade disso, em última análise, aos professores. Para justificar sua posição, expõe 
seis razões: a manipulação do calendário e horário escolares pelos professores em prejuízo dos alunos e famílias, fazendo com que os dias letivos não sejam cumpridos; a inexistência de controle do tempo extraclasse dos professores por parte dos gestores; o fato do professor só se responsabilizar por sua sala de aula; a indiferença e até hostilidade dos docentes em relação à gestão democrática da escola; a constatação de que a direção da escola desmoronou, enquanto instituição, em favor do corpo docente; e o costume do corpo docente de esfriar os ânimos dos professores mais envolvidos com as mudanças, por colocarem em evidência o imobilismo dos demais.

Imediatamente, o texto recebeu críticas de vários educadores, reunidas no mesmo livro, e também de autores muito conhecidos, como Contreras, Imbernón e Sacristán. Traremos apenas as de Contreras. Em resumo, ele considera que Enguita, talvez falando mais como pai de aluno do que como sociólogo, endossa os argumentos do ministro da Educação, reduz as reivindicações dos professores ao nível do fazer pedagógico e acaba sugerindo a necessidade de mais controles sobre os docentes. Questionando a afirmação de Enguita de que a escola pública não está atendendo ao "seu público", Contreras lembra que o caráter público da educação é assegurado em muitas outras instâncias, entre as quais a manifestação pública dos professores sobre as contradições do seu trabalho, que dificultam a realização de um serviço público.

De tudo o que se falou sobre o trabalho docente, seja nas análises dos artigos que apresentamos, seja na polêmica posta por Enguita (2002), queremos lembrar ainda que o trabalho docente não pode ser pensado isoladamente, fora das transformações que estão ocorrendo também em outros setores socioeconômicos. O problema de a escola pública estar sendo ou deixando de ser pública não é fato isolado. Algo semelhante está se passando com as diversas instituições e serviços públicos. O fenômeno tem a ver com as mudanças no mundo do trabalho e emprego, que tentam submeter também os servidores públicos a um tipo de gestão inspirado na lógica de mercado. Regulação, controle e avaliação por competências não são exclusivos do trabalho docente, embora se tornem duplamente problemáticos quando aplicados a ele. De um lado, por se tratar de estratégias de gestão importadas, quase todas, do setor secundário da economia, especialmente das fábricas, e aplicadas à escola como se essa transposição pudesse ser mecânica. Qualquer crítica ou resistência, especialmente dos professores, é vista 
como corporativismo e até mesmo como negação da eficiência pretendida pelo sistema. De outro lado, o fato de os professores realizarem um trabalho intelectual (Giroux, 1997) torna inviável grande parte dessas estratégias em relação ao trabalho docente, que, como trabalho intelectual, não pode ser dividido em partes inteiramente controláveis, previsíveis e avaliáveis quantitativamente.

\section{O trabalho docente como interação social}

Falar sobre o trabalho docente é falar sobre nossa vida, ou pelo menos de uma parte muito importante dela. No caso do professor, é impossível separar sua vida de seu trabalho. Não sabemos se em outras ocupações isso é possível, mas talvez no magistério essa ligação fique mais evidente, já que se trata de um ofício que envolve, todo o tempo, o trabalhador em sua teia de relações com outras pessoas, alunos, colegas, funcionários, pais. Vários dos autores que visitamos através das páginas de E\&S se referiram a este aspecto, mas é no artigo de Gatti e outras (1994) que ele aparece mais claramente, pelos dados colhidos em sua pesquisa, revelando as boas relaçōes no trabalho escolar como o principal fator de satisfação dentro do magistério.

Num salto para um artigo recente, de autora ainda pouco conhecida entre nós, Lanthaume (2007), vemos esse aspecto abordado em uma perspectiva instigante, centrada na idéia do "bom trabalho", aplicada à análise da situação atual em que o professor realiza o seu trabalho. A pesquisa de Lanthaume se refere ao professor na França, seu país, mas contém sugestões oportunas para as nossas análises. Seu ponto de partida remonta aos estudos da sociologia interacionista, com sua percepção da importância das interações ligadas aos processos biográficos e da dimensão subjetiva do trabalho, na construção dos grupos profissionais. Essa preocupação aproxima-se do que acontece no magistério, nunca constituído inteiramente como uma "profissão unificada”, segundo a autora, no sentido desenvolvido pela sociologia funcionalista anglo-saxônica das profissões.

A pesquisadora francesa, em seu estudo com 500 professores, estava especialmente interessada em verificar quais são as reações dos docentes, dentro desse quadro atribulado, lá como cá, no contexto do estabelecimento escolar e tendo como pano de fundo a concepção de fazer 
um "belo trabalho", compromisso construído historicamente pelo ofício. A importância de conseguir realizar um "bom trabalho" se junta à incerteza sobre a própria definição do que seja um "bom trabalho", para o professor, o que, na visão da autora, é fator de estabilização na constituição de outras profissões, como ensina a sociologia das profissões. Ela aponta os efeitos negativos sobre o trabalho, e mesmo a saúde dos docentes, de fatores como a massificação da educação, a desregulação, a redefinição de tarefas, como sintomas de uma crise no ofício, tendo como um dos indicadores a ausência de acordo sobre a definição de um "bom trabalho" e a fraqueza dos debates sobre estas questões. O simples empenho individual para manter a situação estabilizada não substitui os recursos do coletivo, de um ofício com regras e princípios unindo seus profissionais. A autora associa o estado do ofício docente a um estado de crise, entendida como um processo de redefiniçãa dos pontos de referência e de adaptação a universos sociais muito mutáveis. É possível que assim o ofício docente se redefina progressivamente, numa evolução que implica sofrimentos "ordinários" no nível do trabalho individual, mas demanda esforços de uma sociologia que possa contribuir para melhor compreender esse processo tanto no nível micro, como no macro.

A menção do sofrimento ordinário no texto de Lanthaume evoca a obra do sociólogo francês Dejours (1998), que desenvolveu uma análise comovente da evolução do trabalho em seu país, após a Segunda Guerra Mundial. O próprio título do livro - Souffrance en France - já indica o caráter pungente da análise e seu subtítulo esclarece ainda mais a intenção do autor de desvelar o lado perverso daquela evolução: "A banalização da injustiça social”. Faremos apenas menção a uma de suas idéias, que nos parece diretamente vinculada a um sentimento muito presente entre nossos professores, hoje, e que o autor considera fundamental para todo trabalhador: sentir seu trabalho reconhecido como importante. Não é difícil voltar os olhos para um passado não muito distante para ver, entre nós, um professor que não tinha dúvidas sobre a importância reconhecida do seu trabalho, independentemente da discussão sobre outros aspectos de sua ocupação, como salário e condições de atuação. Este tema nos parece merecer uma consideração atenta, de modo especial pelos cursos de formação, mas também pela literatura da área e pela mídia, que muitas vezes trabalha na direção oposta. 
Numa contribuição recente (2006), o sociólogo espanhol J. M. Esteve, muito conhecido entre nós por sua obra sobre o mal-estar docente (1987), em perspectiva bem mais positiva, propóe quatro objetivos ligados ao êxito ou ao fracasso do ensino, importantes para a formação do futuro professor. $\mathrm{O}$ primeiro consiste na elaboração da própria identidade pelo futuro docente, sem se deixar levar por idealizações que o desviem do verdadeiro sentido do seu trabalho. Este desvio ocorre, segundo o autor, pela busca do modelo do "bom professor", e do que ele deve fazer ou evitar, mas o problema de encontrar uma identidade profissional estável passa por um processo de reconversão, "no qual o elemento central consiste em compreender que a essência do trabalho do professor é estar a serviço da aprendizagem do aluno” (p. 59). O segundo objetivo é dominar as técnicas básicas de comunicação e interação na aula. O terceiro consiste na organização do trabalho em classe, que exige uma disciplina mínima para trabalhar em grupo. Finalmente, o quarto objetivo consiste em adaptar os conteúdos ao nível dos alunos. De nada adianta reclamar do nível insuficiente com que chegam os alunos: temos que nos "liberar dos estilos acadêmicos do investigador especialista e adquirir o enfoque da matéria para fazê-la acessível ao grupo de alunos", diz Esteve. E conclui, de forma eloqüente, que há tempos descobriu que, "em qualquer disciplina, o único verdadeiramente importante é tentar ser professor de humanidade" (p. 63). Esta é a mensagem que escolhe para encerrar seu longo texto, afirmando que formar mestres de humanidade é um objetivo para reconstruir a identidade profissional de nossos docentes.

\section{Velhos e novos desafios ao trabalho docente}

Em contraposição a um quadro preocupante sobre a profissão docente, no qual reconhecemos posições de vários dos articulistas que analisamos, trazemos um estudo recente de Tenti Fanfani (2005), comparando quatro países da América Latina, com dados bastante promissores sobre alguns aspectos do magistério na educação básica. No Brasil, segundo essa pesquisa, a maioria dos professores se vê como classe média baixa $(51,6 \%)$, mas os dados sobre o ingresso per capita por residência mostram que $68,7 \%$ deles situam-se nos dois quintis mais favorecidos (p. 40 e 51). O mesmo survey indica que 62,4\% declaram ter condiçôes econômicas melhores que as de seus pais e mais de $80 \%$ 
acham que daqui a cinco anos estarão em situação econômica igual ou melhor do que a atual (p. 56 e 57). Outros dados indicam apenas 9,1\% dos docentes trabalhando em três ou mais estabelecimentos de ensino (p. 86) e 79,3\% manifestando alta satisfação com a atividade docente em si mesma (p. 101), sendo que 62,5\% se dizem igualmente ou mais satisfeitos hoje que no início da carreira (p. 103).

O termo condição docente, proposto por Tenti Fanfani (2005), oferece uma perspectiva interessante para a consideração do trabalho docente. Comporta a dimensão de risco presente na precarização dessa atividade, assim como riquezas e possibilidades do métier. Possibilita a consideração de aspectos dificilmente revelados pela accountability do estado avaliador, ao se aproximar de situações concretas de atuação de docentes e suas liçôes. A idéia de ergonomia, aplicada à docência de forma diversa daquela que vem sendo desenvolvida na área da saúde, tem sido apresentada aqui no Brasil por Therrien e Loyola (2001), entre outros. Tanto na área da saúde quanto na da educação, a ergonomia estuda a relação do trabalhador com o seu contexto de trabalho. Entretanto, na saúde ela busca, sobretudo, assegurar o bem-estar do trabalhador, enquanto que na educação, além disso, visa à eficácia do próprio trabalho, desvendando aspectos decisivos do "saber-ensinar-bem" e da própria transmissão desse saber na formação inicial. Mesmo em condiçôes frágeis, o professor pode obter êxito em algum aspecto do seu trabalho, que merece ser estudado. Nas limitações da rotatividade e itinerância (Sampaio \& Marin, 2004) e de outras situações desfavoráveis, a perspectiva ergonômica poderá vislumbrar o diferencial do sucesso para ajudar a organizar melhor o trabalho de todos os professores. Ainda que não tenha estudado diretamente o magistério, Dubar (2000) contribui para esta linha de pesquisa, ao explicar a adaptação dos trabalhadores de grandes indústrias a novas organizações de produção, por meio da análise das novas situações de trabalho.

\section{De novo e sempre a profissão docente}

A vasta questão que envolve os conceitos de profissão, profissionalidade, profissionalismo, desenvolvimento profissional, identidade profissional, formando uma espécie de conglomerado ou complexo conceitual, está na base de toda discussão sobre o trabalho docente, envolvendo necessariamente o aspecto relativo à formação do futuro e 
do atual profissional do magistério. Todos esses conceitos compareceram na pena dos nossos autores e são também objeto de uma vasta literatura desenvolvida por colegas da nossa comunidade educacional e de outros países. Nós mesmos já trabalhamos diretamente sobre os conceitos de profissão e profissionalidade docentes em artigo produzido para E\&̛S (Lüdke \& Boing, 2004) e não pretendemos retomálo aqui. Achamos mais oportuno trazer algumas contribuições recentes que, a nosso ver, avançam a reflexão sobre alguns problemas centrais ao nosso tema.

Um trabalho da pesquisadora chilena Avalos (2006), sobre o que denomina "el nuevo profesionalismo", propõe uma redefinição do conceito tradicional de profissão, que se aplica dificilmente à docência, por meio desse novo profissionalismo, onde a preocupação com a qualidade da formação inicial é destacada. Com base em contribuições de autores, como Hargreaves, Avalos chama a atenção para a complexidade e a variedade de competências que precisam ser desenvolvidas pelo professor e sobre o desafio posto assim à formação de futuros professores. E desenvolve, a partir daí, um argumento interessante, ainda que possivelmente controverso, sobre a formação dos formadores de docentes, chegando a dizer que "em sistemas concorrentes universitários (incluindo universidades pedagógicas) não existe clareza sobre quem são propriamente formadores de docentes" (p. 219). Há toda uma discussão a ser feita e sendo já feita entre nós, a respeito dessa delicada questão, na qual nos parece que a responsabilidade das faculdades de educação se revela bem maior do que temos conseguido avaliar.

Em artigo publicado neste ano, Roldão (2007) toca de maneira muito pertinente em um ponto muito sensível do nosso tema: o conceito de ensinar. Ele merece especial destaque, por se tratar de um aspecto que chamaríamos, um tanto pretensiosamente, de ontológico: Qual é o traço essencial que distingue a função, a tarefa, a responsabilidade, a expertise, o que é específico, próprio do professor? Ao considerar o ensino como a função própria do profissional docente, pode-se resvalar para a redução dessa função à simples transmissão de conhecimentos, o que tem dado ensejo à consideração crítica do professor como mero transmissor, idéia antiga e ainda corrente, que costuma irritar profundamente a comunidade de pesquisadores em educação, mas não se conseguiu extirpar da literatura menos acadêmica e, de modo especial, da mídia. Por outro lado, temos contribuiçōes importantes, dentro da 
academia, que alertam para a distância entre o trabalho do ensino e o da aprendizagem, cada um se colocando em pólos não propriamente opostos, mas por certo diferentes, o que nos deixa em uma situação de suspense, sem conseguir atingir com propriedade uma concepção desse "próprio" do professor. Roldão consegue, a nosso ver, caminhar um bocado na direção de uma visão mais ampla e ao mesmo tempo mais frutífera do conceito de ensinar. Ela anuncia logo que, do jeito que vem sendo entendido, trata-se de um conceito anacrônico (o de ensinar), face às inúmeras transformações pelas quais vem passando o magistério. Segundo a autora, "a função específica, definidora do profissional professor, não reside na passagem do saber, mas sim na função de ensinar, e ensinar não é apenas, nem sobretudo, "passar" um saber (...). A especificidade da função de ensinar situa-se em fazer com que o outro aprenda. E essa é a essência da profissionalidade docente" (p. 36). No restante do artigo, a pesquisadora discute os desafios de se levar adiante essa bandeira no trabalho de formação de professores.

Não podemos concluir esta seção sem mencionar a contribuição de Tardif e Lessard (2007), exatamente sobre um aspecto complementar ao apresentado por Roldão: o foco na interação como essencial ao trabalho docente, o que deveria ser mais considerado na formação do professor. Há muito esses autores vêm desenvolvendo uma linha de pesquisa sobre a formação do professor, em íntima conexão com seu trabalho, estimulando um fértil debate sobre o saber docente, essencialmente ligado à prática do professor.

\section{Ao fim do percurso}

O itinerário do tema "trabalho docente" nas páginas de Educação \& Sociedade, ainda que traçado de forma rápida, permite observar pontos de grande interesse, embora não esgotem os inúmeros aspectos que merecem atenção especial, ao se tratar de tema tão central para a sociedade atual. Como revelam vários autores, entre os quais Dubar (2000), Dejours (1998) e outros, o quadro no qual se insere o trabalho de forma geral, hoje, apresenta-se como muito complexo, com enigmas, ambivalências e mesmo contradições. Em seu número de fevereiro de 2007, a revista Sciences Humaines dedica ao tema "trabalho" um dossiê muito expressivo. Tratando da França e de outros países europeus, com base em investigaçóes junto a trabalhadores de diferentes 
categorias, são apresentados dados muito instigantes e sugestivos para nossa reflexão (Fournier, 2007). O "valor trabalho" ocupa, neste início de século, o segundo lugar, logo depois da família, e os argumentos apresentados para justificar a escolha "são sempre os da independência que o trabalho proporciona e a realização de si que ele autoriza" (p. 32). Então, por que essa depressão entre os trabalhadores, esse malestar que emana do mundo do trabalho? Para compreendê-lo é preciso lançar um olhar às constatações objetivas e aos discursos subjetivos que delas decorrem, diz a autora. E prossegue: é preciso considerar, ao mesmo tempo, os novos funcionamentos das organizações contemporâneas e as representações do trabalho que emergiram do individualismo contemporâneo. Para os trabalhadores mais qualificados, parece que a situação atual, de maior responsabilidade individual no trabalho, permite o florescimento de recursos pessoais, de competências próprias e úteis ao desenvolvimento de suas carreiras. Muitos deles dizem que vivem sua atividade profissional como uma "paixão", uma "aventura”, uma "realização de si". Para 70\% deles o trabalho traz grande satisfação, o que ocorre apenas com 30\% dos operários não-qualificados. Esses são dados de uma pesquisa de Baudelot e Gollac, citada no dossiê, que explicam, com certa ironia, que "a felicidade no trabalho está em cima e o sofrimento, sobretudo, embaixo (...)” (p. 34).

Por certo, as circunstâncias que cercam a vida do trabalhador europeu não são exatamente as mesmas que cercam a vida dos nossos trabalhadores. Mas também é certo que tanto entre aqueles que trabalham em condições bem mais favoráveis, como entre os que por aqui labutam, o cenário onde se desenvolve o trabalho tem se alterado radicalmente. Não apenas as evoluções tecnológicas, a ameaça do desemprego, a exacerbação do capitalismo, as exigências da globalização, mas o próprio sentido do trabalho tem sofrido mudanças muito sensíveis, bem analisadas por vários sociólogos. Por certo, o professor sofre as injunções desses e de outros fatores em seu trabalho, mas é forçoso reconhecer que sua posição como "profissional" continua situada em local de destaque em nossa sociedade, pela própria função que desempenha na base estrutural dessa sociedade.

Nossos articulistas se dão conta disso, de diferentes maneiras. Alguns ressaltam a importância das lutas políticas da categoria, embora reconheçam limitaçôes em seu alcance. Outros focalizam aspectos específicos e suas ingerências sobre o exercício da docência, como 
a entrada triunfante das TiCs e da onda de avaliação que se avoluma sobre a vida das escolas, seus professores e alunos, atraindo-os para o pólo dos produtos. Uns poucos avançam para a perspectiva da ergonomia, que poderá possibilitar conhecer de perto práticas bem sucedidas e outras com problemas, de modo a extrair as lições delas decorrentes, que ficariam perdidas sem esse recurso de conhecimento. Muitos tocam no perene ponto-chave da formação, inicial e continuada, na preparação de um profissional mais fortalecido, para enfrentar os embates e desafios de um trabalho docente mutante, frente a uma população discente ainda mais mutante. Outra fortaleza estaria na formação para a pesquisa e sua prática para o desenvolvimento profissional do professor, como um dos braços ativos da profissionalidade no magistério.

Nos trilhos de Educação \& Sociedade, sobre os quais se move o tema do trabalho docente, encontra-se, velada ou implícita em quase todos os artigos, a questão da especificidade da função do magistério frente às demais ocupações. Trouxemos alguns aliados externos à Revista, mas não ao tema, para reforçar esse aspecto que consideramos essencial. Foi o caso de Esteve (2006), que o agarra pelo atalho do "ensino de humanidade", como raiz para a construção da identidade do professor, escapando dos limites, quase inevitáveis até agora, das disciplinas e da metodologia. Foi o caso também de Roldão (2007), que procura avançar sobre o fosso "ensino-aprendizagem" pelo foco no "fazer com que o outro aprenda" como "essência da profissionalidade docente” (p. 36). Enfim, para garantir a plena realização desse atributo essencial, é necessário trabalhar na tensão entre a dimensão individual e coletiva da profissão docente. Uma proposta prática que vai nesta linha é a do desenvolvimento de "políticas estruturais" (Gentili et al., 2004), que não dependam de pessoas que, em cargos superiores dos sistemas, de caráter passageiro, como ministros e secretários, gerenciam políticas de cima para baixo. Ao invés, políticas do e pelo professor estariam ligadas ao próprio estabelecimento de ensino, como espaço privilegiado da mobilização sindical (Boing, 2002). Partiriam de uma agenda articulada, envolvendo todos os atores que compóem o sistema, num debate sobre o projeto público para a educação, não de governos, mas do Estado. Um dos possíveis passos nessa direção poderia ser a busca de consensos mínimos em torno do trabalho docente.

Recebido em junho de 2007 e aprovado em julho de 2007. 


\section{Referências bibliográficas}

\section{Artigos de Educação \& Sociedade analisados}

ARROYO, M.G. Operários e educadores se identificam: que rumos tomará a educação brasileira? Educação \& Sociedade, Campinas, v. 2, n. 5, p. 5-23, jan. 1980.

BARRETO, R.G. Tecnologia e educação: trabalho e formação docente. Educação \& Sociedade, Campinas, v. 25, n. 89, p. 1181-1201, dez. 2004.

BORGES, C.; TARDIF, M. Apresentação. Educação \& Sociedade, Campinas, v. 22, n. 74, p. 11-26, abr. 2001.

CASTRO, L.R. De assalariado a interlocutor maior: sobre o engajamento militante no magistério. Educação \& Sociedade, Campinas, v. 11, n. 37, p. 85-98, dez. 1990.

FREITAS, H.C.L. Certificação docente e formação do educador: regulação e desprofissionalização. Educação \& Sociedade, Campinas, v. 24, n. 85, p. 1095-1124, dez. 2003.

GATTI, B.G.; ESPOSITO, Y.L.; SILVA, R.N. Características de professores(as) de $1^{\circ}$ grau no Brasil: perfil e expectativas. Educação \& Sociedade, Campinas, v. 15, n. 48, p. 248-260, ago. 1994.

GENTILI, P. et al. Reforma educativa y luchas docentes em América Latina. Educação \& Sociedade, Campinas, v. 25, n. 89, p. 1251-1274, dez. 2004.

HAGUETE, A. Educação: bico, vocação ou profissão? Educação \& Sociedade, Campinas, v. 12, n. 38, p. 109-120, abr. 1991.

LEVASSEUR, L.; TARDIF, M. Divisão do trabalho e trabalho técnico nas escolas de sociedades ocidentais. Educação \& Sociedade, Campinas, v. 25 , n. 89 , p. 1275-1297, dez. 2004.

LÜDKE, M. O professor, seu saber e sua pesquisa. Educação \& Sociedade, Campinas, v. 22, n. 74, p. 77-96, abr. 2001.

LÜDKE, M.; BOING, L.A. Caminhos da profissão e da profissionalidade docentes. Educação \& Sociedade, Campinas, v. 25, n. 89, p. 11591180, dez. 2004. 
MELO, M.T.L. Programas oficiais para formação dos professores da educação básica. Educação \& Sociedade, Campinas, v. 20, n. 68, p. 45-60, dez. 1999.

OLIVEIRA, D.A. A reestruturação do trabalho docente: precarização e flexibilização. Educação \& Sociedade, Campinas, v. 25, n. 89, p. 1127-1144, dez. 2004.

OLIVEIRA, D.A. Regulação das políticas educacionais na América Latina e suas conseqüências para os trabalhadores docentes. Educação \& Sociedade, Campinas, v. 26, n. 92, p. 753-775, 2005.

QUEIROZ, G.R.P.C. Processos de formação de professores artistasreflexivos de Física. Educação \& Sociedade, Campinas, v. 22, n. 74, p. 97-119, abr. 2001.

REIS, E.J.F.B. et al. Docência e exaustão emocional. Educação \& Sociedade, Campinas, v. 27, n. 94, p. 229-253, abr. 2006.

SAMPAIO, M.M.F.; MARIN, A.J. Precarização do trabalho docente e seus efeitos sobre as políticas curriculares. Educação \& Sociedade, Campinas, v. 25, n. 89, p. 1203-1225, dez. 2004.

SANTOS, L.L.C.P. Formação de professores na cultura do desempenho. Educação \& Sociedade, Campinas, v. 25, n. 89, p. 1145-1157, dez. 2004.

SOBREIRA, H.G. Alguns aspectos da reorganização do movimento dos professores públicos do Estado do Rio de Janeiro (1977-1980). Educação \& Sociedade, Campinas, v. 22, n. 77, p. 131-160, dez. 2001.

THERRIEN, J. O saber social da prática docente. Educação \& Sociedade, Campinas, v. 14, n. 46, p. 408-418, dez. 1993.

THERRIEN, J.; LOIOLA, F.A. Experiência e competência no ensino: pistas de reflexóes sobre a natureza do saber-ensinar na perspectiva da ergonomia do trabalho docente. Educação \& Sociedade, Campinas, v. 22, n. 74, p. 143-160, abr. 2001.

\section{Demais referências}

AVALOS, B. El nuevo profesionalismo: formación docente inicial y continua. In: Tenti Fanfani, E. El oficio de docente. Buenos Aires: Siglo Veintiuno, 2006. 
BOING, L.A. A escola como instituição de trabalho e de formação de professores. 2002. Dissertação (Mestrado) - Pontifícia Universidade Católica do Rio de Janeiro, Rio de Janeiro.

DEJOURS, C. Souffrance en France, la banalisation de l'injustice sociale. Paris: Seuil, 1998.

DUBAR, C. La crise des identités. Paris: PUF, 2000.

ENGUITA, M.F. ¿Es publica la escuela publica?. Barcelona: Cisspraxis, 2002.

ESTEVE, J.M. El malestar docente. Barcelona: Laia, 1987.

ESTEVE, J.M. Identidad y desafíos de la condición docente. In: Tenti Fanfani, E. El oficio de docente. Buenos Aires: Siglo Veintiuno, 2006.

FOURNIER, M. Travail: ce douloureux objet de désir. Sciences Humaines, Paris, n. 179, p. 32-35, 2007. Disponível em: <www. scienceshumaines.com>.

GIROUX, H.A. Os professores como intelectuais. Porto Alegre: ARTMED, 1997.

LANTHAUME, F. Mal-estar docente ou crise do ofício?: quando o "belo trabalho" desaparece e é preciso "trabalhar de corpo e alma". Fórum Sociológico, Lisboa, n. 15-16, p. 141-156, 2007.

LÜDKE, M. Educador: um profissional? In: CANDAU, V. Rumo a uma nova didática. Petrópolis: Vozes, 1988.

LÜDKE, M. Sobre a socialização profissional de professores. Cadernos de Pesquisa, São Paulo, n. 99, p. 5-15, 1996.

LÜDKE, M. (Coord.). O professor e a pesquisa. Campinas: Papirus, 2001.

LÜDKE, M. El trabajo y el saber del docente: nuevos y viejos desafíos. In: Tenti Fanfani, E. El oficio de docente. Buenos Aires: Siglo Veintiuno, 2006.

LÜDKE, M.; CRUZ, G.B. Aproximando universidade e escola de educação básica pela pesquisa. Cadernos de Pesquisa, São Paulo, n. 125, p. 81-109, 2005. 
ROLDÃO, M.C. Formar para a excelência profissional: pressupostos e rupturas nos níveis iniciais da docência. Educação \& Linguagem, São Paulo, v. 10, n. 15, p. 18-42, 2007.

TARDIF, M.; LESSARD, C. O trabalho docente. 3. ed. Petrópolis: Vozes, 2007.

TENTI FANFANI, E. La condición docente. Buenos Aires: Siglo Veintiuno, 2005. 